\title{
ANALISIS KESEHATAN LAPORAN KEUANGAN PADA PT BPR SYARIAH BUANA MITRA PERWIRA DENGAN MENGGUNAKAN METODE CAMEL TAHUN 2016 - 2020
}

\author{
Laila Maghfiroh ${ }^{1, *}$ \\ Program Studi Ekonomi Syariah, UIN Sunan Ampel Surabaya, Surabaya, Indonesia \\ g74219104@student.uinsby.ac.id \\ ${ }^{*}$ Corresponding author \\ Muhammad Iqbal Surya Pratikto² \\ Program Studi Ekonomi Syariah, UIN Sunan Ampel Surabaya, Surabaya, Indonesia \\ m.iqbal@uinsby.ac.id
}

\begin{abstract}
Background - Financial Health of the People's Credit Bank There is an assessment to reflect the role of economic policy, to determine the target and assess the financial health of a bank in a certain period, so that it can be used to analyze and as an evaluation to be able to know the performance of banking management.

Purpose - In the Aspect of Camel Assessment have quantification of financial ratio calculations that are useful for assessing the level of financial health of the bank, the higher the capital of the bank that is expected to be the better the performance of its operations and the greater the scale of the operation, the bank is measured by total assets.

Design / Methodology / Approach - This research researchers used quantitative research methods. To be able to achieve the objectives need to present an important indicator to determine the financial condition of PT $B P R$ Syariah Buana Mitra Officers.

Results and Discussion - The results of the study show that the health level at PT BPR Syariah Buana Mitra Officers in 2016-2020 can be declared very healthy. This means that at this time PT BPR Syariah Buana Perwira is able to guarantee customers for every deposit provided by the Customer and can pay all its obligations in the form of savings deposits, demand deposits, deposits when billed and can fulfill all credit applications that are approved .

Conclusion - Car Ratio Analysis, PDN ratio, ROE RATIO, BOPO, NI and NPF ratio analysis at PT BPR Syariah Buana Mitra Officers in 2016- 2020 categorized are very healthy. While the analysis of Rentability using RAA ratio at PT BPR Syariah Buana Mitra Officers in 2016-2020 is categorized as healthy. While the FDR ratio analysis is categorized enough healthy.

Research implications - this study can be used as a basis for the financial level of financial levels for the people's credit banks which are currently popping up. With this analysis, it will make BPR managers to be able to predict how the health level of BPR finance is adjusted to the conditions at this time.
\end{abstract}

Keyword : Financial, Statements, CAMEL, BPR, Syariah, Buana

\begin{abstract}
Abstrak
Latar Belakang - kesehatan keuangan Bank Perkreditan Rakyat terdapat penilaian pada agar dapat mencerminkan peranan terhadapkebijakan ekonomi, untuk mengetahui target dan menilai kesehatan keuangan suatu bank pada periode tertentu, sehingga dapat digunakan menganalisa dan sebagai evaluasi untuk dapat mengetahui kinerja manajemen perbankan.

Tujuan - Dalam aspek penilaian CAMEL memiliki kuantifikasi pada perhitungan rasio keuangan yang bermanfaat untuk menilai tingkat kesehatan keuangan bank, semakin tinggi jumlahmodal dari bank yang
\end{abstract}


diharapkan akan semakin baik kinerja operasinya dan semakin besar skala operasi maka bank diukur dengan total asset.

Desain/ Metodologi/ Pendekatan - Penelitian ini peneliti menggunkan metode penelitian kuantitatif. Untuk dapat mencapai tujuan perlu adanya penyajian indicator-indikator penting untuk mengetahui kondisi keuangan PT BPR Syariah Buana Mitra Perwira.

Hasil dan Pembahasan - Hasil penelitian menunjukkan bahwa tingkat kesehatan pada PT BPR Syariah Buana Mitra Perwira tahun 2016-2020 dapat dinyatakan sangat sehat. Artinya pada jangka waktu tersebut PT BPR Syariah Buana Perwira mampu memberikan jaminan kepada nasabah atas setiap simpanan yang diberikan oleh nasabah serta dapat membayar seluruh kewajiba-kewajibannya dalam bentuk simpanan tabungan, giro, deposito pada saat ditagih dan dapat memenuhi seluruh permohonan kredit yang layak untuk disetujui.

Kesimpulan - analisis rasio CAR, rasio PDN, rasio ROE, BOPO, NI dan analisis rasio NPF di PT BPR Syariah Buana Mitra Perwira tahun 2016-2020 dikategorikan sangat sehat. Sedangkan analisis Rentabilitas menggunakan rasio ROA pada PT BPR Syariah Buana Mitra Perwira tahun 2016-2020 dikategorikan sehat. Sementara analisis rasio FDR dikategorikan cukup sehat.

Implikasi penelitian - Penelitian ini dapat dijadikan sebagai dasar penilaian tingkat kesehatan keuangan bagi Bank Perkreditan Rakyat yang saat ini sudah banyak bermunculan. Dengan adanya analisis ini akan menjadikan pengelola BPR untuk dapat memprediksi bagaimana tingkat kesehatann keuangan BPR-nya disesuaikan dengan kondisi yang dihadapi saat ini.

Kata Kunci : Laporan, Keuangan, CAMEL, BPR, Syariah, Buana

\section{PENDAHULUAN}

Sistem penilaian tingkat kesehatan keuangan bank memiliki sifat dinamis, merupkan penilaian kondisi keungan yang dapat mencerminkan tingkat kesehatan keuangan bank, seperti tabungan, giro, simpanan, dan deposito. Bank sebagai tempat penyimpanan uang bagi masyarakat yang ada kelebihan dana, selain itu bank juga sebagai tempat meminjam dana bagi masyarakat yang kekurangan dana. Bank memberikan kepuasan bagi masyarakat yang membutuhkan bank dalam meminjam dan menyimpan dana mereka, oleh karena itu bank mengadakan produk dan layanan untuk memuaskan masyarakat atau nasabah, serta memberikan kemudahan untuk para masyarakat yang meminjam dan menyimpan dana mereka, serta bank juga menyediakan alat pembayaran dan mekanisme agar dapat mempermudah bertransaksi, dan juga menjamin keamanan simpanan dana. Lembaga keuangan yang sangat strategis dapat menempatkan bank danmemperlancar seluruh kegiatan ekonomi masyarakat dan juga mempermudah.

Pembangunan ekonomi merupakan suatu tujuan untuk dapat meningkatkan taraf hidup rakyat Indonesia. Ketika krisis ekonomi timbul Bank Perkreditan Rakyat sebagai lembaga keuangan yang selalu ada dalam mengatasi masalah-masalah yang timbul. Tujuan dari Bank Perkreditan adalah selalu tetap ada dan berkembang pada hasil operasionalnya, untuk dapat mengetahui 
tingkat kesehatan Bank Perkreditan rakyat perlu adanya pengukuran dalam pengelolaan usaha Bank Perkreditan Rakyat dengan asas-asas dan ketentuan yang berlaku yang dapat diketahui ketika menganalisis tingkat kesehatan lembaga keungan syariah, yakni Bank Perkreditan Rakyat.

Tingkat kesehatan bank menjadi sebuah kepentingan semua yang terlibat dalam ruang lingkup perbankan, dari pihak Bank Indonesia sebagai otoritas pengawasan bank dan pihak pemilik, pengelola serta nasabah bank. Hal ini dilakukan untuk dapat digunakan evaluasi kinerja bank dengan hati-hati. Dalam penilai kesehatan bank dilakukan dengan menggunakan faktorfaktor Capital, Aset, Quality, Management, Earning, dan Liquidity, penilaian tingkat kesehatan keuangan bank dari berbagai aspek, bank menggunakan lima faktor yakni pada permodalan, kualitas, aktiva produktif, manajemen, rentabilitas, dan likuiditas (Azwa \& Afriani, 2014). Terdapat kriteria seberapa besar presentasi kinerja keuangan yang ada pada ketentuan Bank Indonesia dalam memenuhi persyaratan kesehatan bank, sehingga tidak menimbulkan kerugian bagi pihak yang membutuhkan. Dalam aspek penilaian CAMEL memiliki kuantifikasi pada perhitungan rasio keungan yang bermanfaat untuk mengetahui kesehatan keuangan bank, semakin baik kinerjanya maka semakin tinggi jumlah modal dari bank operasinya dan semakin besar skala operasi maka bank diukur dengan total aset.

Untuk itu dalam memahami kemajuan tingkat kesehatan keuangan Bank Perkreditan Rakyat terdapat penilaian pada agar dapat mencerminkan peranan terhadap kebijakan ekonomi, untuk mengetahui target dan menilai kesehatan keuangan suatu bank pada periode tertentu, sehingga dapat digunakan menganalisa dan sebagai evaluasi untuk dapat mengetahui kinerja manajemen perbankan. Untuk dapat mencapai tujuan perlu adanya penyajian indicator-indikator penting untuk mengetahui kondisi keuangan. Mengenai latar belakang tersebut maka penulis ingin meneliti analisis Kesehatan Laporan Keuangan pada PT BPR Syariah Buana Mitra Perwira dengan Menggunakan Metode Camel Tahun 2016 2020"

\section{TINJAUAN PUSTAKA}

\section{Tingkat Kesehatan Bank}

Kesejahteraan merupakan kemampuan suatu bank untuk memimpin tugas-tugas perbankan secara teratur dan memiliki pilihan untuk memenuhi semua persyaratan. tugas dengan tepat dengan cara sesuai pedoman keuangan material. Kesejahteraan keuangan organisasi dapat 
dilihat dari pemeriksaan ringkasan fiskal yang akan memberikan citra keuangan organisasi. Efek dari proporsi moneter akan menunjukkan kondisi kesehatan organisasi. Dengan demikian, yang dimaksud dengan kesejahteraan organisasi adalah keadaan di mana suatu organisasi mencapai prestasi dalam jangka waktu tertentu (Iqbal et al., 2021). Pengelolaan Moneter meliputi pengaturan, penguraian, dan pengendalian latihan moneter. Dengan cara ini cenderung diperjelas bahwa administrasi moneter adalah sebuah gerakan organisasi yang menyoroti cara yang paling efektif untuk mengumpulkan aset dan menggunakan aset tersebut untuk mencapai tujuan suatu perusahaan. Menyadari pentingnya kesejahteraan bank sebagai landasan kepercayaan pada dunia keuangan dan untuk menerapkan pedoman kecermatan dalam dunia keuangan, Bank Indonesia sendiri menerapkan pedoman kesejahteraan bank. Diyakini bahwa semua bank sehat, agar tidak menjadi kelemahan dari pertemuan terkait perbankan (Putri \& Marlius 2018). Pada peraturan Bank Indonesia Nomor 9/1/PBI/2007 tanggal 24 Januari 2008 mengenai Sistem Penilaian Tingkat Kesehatan Bank Umum berdasarkan dengan prinsip syariah yang berlaku, menjelaskan bahwa bank wajib melakukan penilaian tingkat kesahatan bank yang mencakup penilaian terhadap beberapa faktor. Untuk menilai keberhasilan atau kegagalan suatu bank dalam mencapai tujuannya dapat dilihat dengancara melihat laporan keuangan perusahaan yang telah dicapai. Salah satu indikator penilaian kesahatan bank dapat menggunakan metode CAMEL. (Indonesia, n.d.)

\section{Metode Camel}

Capital (modal), Asset (aktiva), Management (manajemen), Earning (rentabilitas), Liquidity (likuditas), dan Sensitivity to market risk (sensitifitas terhadap risiko pasar) yang diangkat menjadi CAMELS merupakan aspek-aspek yang harus dipenuhi dalam penilaian kesehatan bank meliputi Untuk itu, kesehatan suatu bank dapat dilihat dari laporan keuangan yang meliputi aspekaspek tersebut (Jacob et al., 2011). CAR menurut (Hafiz \& Putra, 2018) merupakan rasio yang mempergunakan modal untuk dapat dana yang tinggi untuk keberhasilan suatu bank yang dapat digunakan sebagai bentuk pembiayaan masyarakat, untuk menilai modal pada bank menggunakan rasio CAR (lihat persamaan 1) dengan membandingkan modal pada rasio ATMR, dapat dilihat bahwa faktor utama ATMR. Hasil perhitungan rasio CAR akan diklasifikasikan kedalam tabel konversi yang akan menunjukkan predikat dari hasil 
kriteria CAR (tabel 1).

Asset (Aset Aktiva Produktif) merupakan asset yang dimiliki perusahaan yang sangat penting jika diperbandingkan dengan modal, hal ini dikarenakan asset memiliki fungsi menopang jalanya suatu perusahaan perbankan. Earning asset atau aktiva yangmmenghasilkan merupakan penilaian indikator Aset Non Performing Finance (lihat persamaan 2) (Jafar et al., 2020). Hasil perhitungan rasio NPF akan diklasifikasikan kedalam tabel konversi yang akan menunjukkan predikat dari hasil kriteria NPF (tabel 2).
Management merupakan pengukuran hasil strategi yang berupa proses pendataan, penjagaan, dan mengawasi dalam menjalankan opersional bank dalam mendapatkan operasi revenue yang optimum, pada net income berupaya meminimkan resiko dari rasio likuiditas, risiko kredit, risiko operasional, risiko hukum, dan risiko kepala kegiatan operasional dari perbankan (lihat persamaan 3) (Azwa \& Afriani, 2014). Hasil perhitungan rasio PDN akan diklasifikasikan kedalam tabel konversi yang akan menunjukkan predikat dari hasil kriteria PDN (tabel 3).

$$
\begin{aligned}
& \mathrm{CAR}=\frac{\text { Modal }}{\text { Aset Tertimbang Menurut Risiko (ATMR) }} \times 100 \% \\
& \mathrm{NPF}=\frac{\text { Kredit Bermasalah }}{\text { Total Kredit }} \times 100 \% \\
& \mathrm{PDN}=\frac{\text { Selisih Aset \& Liabilitas Valas }}{\text { Total Modal }} \times 100 \%
\end{aligned}
$$

Tabel 1

Klasifikasi peringkat komposisi CAR

\begin{tabular}{ccl} 
Peringkat & Kriteria & \multicolumn{1}{c}{ Predikat } \\
1 & CAR $\geq 12 \%$ & Sangat Sehat \\
2 & $9 \% \leq \mathrm{CAR}<12 \%$ & Sehat \\
3 & $8 \% \leq \mathrm{CAR}<9 \%$ & Cukup Sehat \\
4 & $6 \% \leq \mathrm{CAR}<8 \%$ & Kurang Sehat \\
5 & $\mathrm{CAR} \leq 6 \%$ & Tidak Sehat \\
\hline
\end{tabular}

Sumber : SE BI No. 6/23/DPNP tahun 2004 
Tabel 2

Klasifikasi peringkat komposisi NPF

\begin{tabular}{ccl} 
Peringkat & Kriteria & \multicolumn{1}{c}{ Predikat } \\
\hline 1 & $\mathrm{NPF} \leq 2 \%$ & Sangat Sehat \\
2 & $2 \% \leq \mathrm{NPF}<5 \%$ & Sehat \\
3 & $5 \% \leq \mathrm{NPF}<9 \%$ & Cukup Sehat \\
4 & $8 \% \leq \mathrm{NPF}<12 \%$ & Kurang Sehat \\
5 & $\mathrm{NPF} \geq 12 \%$ & Tidak Sehat \\
\hline
\end{tabular}

Sumber: SE BI No. 6/23/DPNP tahun 2004

Tabel 3

Klasifikasi peringkat komposisi PDN

\begin{tabular}{cll} 
Peringkat & \multicolumn{1}{c}{ Kriteria } & \multicolumn{1}{c}{ Predikat } \\
1 & Tidak ada pelanggaran rasio PDN & Sangat Sehat \\
2 & $\begin{array}{l}\text { Tidak melakuan pelanggan rasio PDN namun pernah } \\
\text { melakukan pelanggaran dan telah diselesaikan }\end{array}$ & Sehat \\
3 & Pelanggaran rasio PDN $>0 \%$ sampai dengan $<10 \%$ & Cukup Sehat \\
4 & Pelanggaran rasio PDN $>10 \%$ sampai dengan $<25 \%$ & Kurang Sehat \\
5 & Pelanggaran rasio PDN $>25 \%$ & Tidak Sehat
\end{tabular}

Sumber : SE BI No. 6/23/DPNP tahun 2004

Earnings (Aspek Rentabilitas) merupakan pengujian manfaat setelah dibebankan pada modal atau manfaat sebelum dibebankan dengan semua sumber daya yang dimiliki oleh bank dalam waktu tertentu. Semua bersama-sama untuk konsekuensi dari perhitungan proporsi mendekati keadaan sebenarnya, posisi modal ditentukan pada normal selama waktu tersebut. (Hafiz \& Putra, 2018).

1. ROA

ROA (lihat persaman 4) merupakan salah satu ukuran mengenai efektivitas dari manajemen dalam memanfaatkan aktivanya untuk memperoleh laba (Sari 2019). Hasil perhitungan rasio ROA akan diklasifikasikan kedalam tabel konversi yang akan menunjukkan predikat dari hasil kriteria ROA (tabel 4).

2. $\mathrm{ROE}$

Rasio ini (lihat persamaan 5) digunakan untuk pengendalian terhadap biaya operasional dan mengukur kemampuan manajemen bank dalam melakukan akan menunjukkan efensiensi penggunaan modal sendiri yang terhadap pendapatan operasional. Hasil perhitungan rasio ROE akan diklasifikasikan kedalam tabel konversi yang akan menunjukkan predikat dari hasil kriteria ROE (tabel 5). 
3. $\mathrm{BOPO}$

BOPO (lihat persamaan 6) merupakan rasio yang digunakan perbankan dalam mengukur tingkat efesiensi kemampuan lembaga keuangan untuk melakukan kegiatan operasionalnya. Hasil perhitungan rasio BOPO akan diklasifikasikan kedalam tabel konversi yang akan menunjukkan predikat dari hasil kriteria BOPO (tabel 6).

4. NI

Rasio NI (lihat persamaan 7) merupakan rasio yang digunakan oleh lembaga keuangan maupun perusahaan untuk mengukur besarnya pendapatan imbalan bersih yang dihasilkan dari aktiva produktif. Hasil perhitungan rasio NI akan diklasifikasikan kedalam tabel konversi yang akan menunjukkan predikat dari hasil kriteria NI (tabel 7).

$$
\begin{aligned}
& \mathrm{ROA}=\frac{\text { Laba Sebelum Pajak }}{\text { Rata-rata Total Aset }} \times 100 \% \\
& \mathrm{ROE}=\frac{\text { Laba Setelah Pajak }}{\text { Rata-rata Total Modal }} \times 100 \% \\
& \mathrm{BOPO}=\frac{\text { Biaya Operasional }}{\text { Pendapatan Operasional }} \times 100 \% \\
& \mathrm{NI}=\frac{\text { Pendapatan Imbalan }}{\text { Rata-rata Aset Produksi }} \times 100 \% \\
& \mathrm{FDR}=\frac{\text { Jumlah Kredit yang Diberikan }}{\text { Total Dana Pihak Ke-3 }} \times 100 \%
\end{aligned}
$$

5. Likuiditas

Likuiditas (Aspek Likuiditas) merupakan kewajiban bagi perusahaan dalam memenuhi besar kecilnya aktiva lancar pada financial jangka pendek, yang dapat memberikan evaluasi pada suatu bank pada tingkat risiko diukur dengan indicator Finance to Deposit Ratio (FDR) (lihat persamaan 8). Likuiditas juga dapat membayar biaya, menyimpan catatan, memberikan simpanan berjangka, dana akan berkembang dan menutup kebutuhan kredit, jika kapasitas bank untuk memenuhi komitmen jangka pendek. (Syahputra, 2018). Hasil perhitungan likuiditas akan diklasifikasikan kedalam tabel konversi yang akan menunjukkan predikat dari hasil kriteria likuiditas (tabel 8). 
Tabel 4

Klasifikasi peringkat komposisi ROA

\begin{tabular}{ccl} 
Peringkat & Kriteria & \multicolumn{1}{c}{ Predikat } \\
1 & $\mathrm{ROA} \geq 2 \%$ & Sangat Sehat \\
2 & $1,26 \% \leq \mathrm{ROA}<5 \%$ & Sehat \\
3 & $0,51 \% \leq \mathrm{ROA}<1,25 \%$ & Cukup Sehat \\
4 & $0 \% \leq \mathrm{ROA}<0,5 \%$ & Kurang Sehat \\
5 & $\mathrm{ROA}<0 \%$ & Tidak Sehat
\end{tabular}

Sumber : SE BI No. 6/23/DPNP tahun 2004

Tabel 5

Klasifikasi peringkat komposisi ROE

\begin{tabular}{ccl} 
Peringkat & Kriteria & \multicolumn{1}{c}{ Predikat } \\
1 & $\mathrm{ROE} \geq 20 \%$ & Sangat Sehat \\
2 & $12,51 \% \leq \mathrm{ROE}<20 \%$ & Sehat \\
3 & $5,01 \% \leq \mathrm{ROE}<1,25 \%$ & Cukup Sehat \\
4 & $0 \% \leq \mathrm{ROE}<5 \%$ & Kurang Sehat \\
5 & $\mathrm{ROE}<0 \%$ & Tidak Sehat \\
\hline
\end{tabular}

Sumber : SE BI No. 6/23/DPNP tahun 2004

Tabel 6

Klasifikasi peringkat komposisi BOPO

\begin{tabular}{ccl} 
Peringkat & Kriteria & \multicolumn{1}{c}{ Predikat } \\
1 & BOPO $<88 \%$ & Sangat Sehat \\
2 & $89 \% \leq \mathrm{BOPO}<93 \%$ & Sehat \\
3 & $94 \leq \mathrm{BOPO}<96 \%$ & Cukup Sehat \\
4 & $97 \% \leq \mathrm{BOPO}<100 \%$ & Kurang Sehat \\
5 & $\mathrm{BOPO}>100 \%$ & Tidak Sehat \\
\hline
\end{tabular}

Sumber : SE BI No. 6/23/DPNP tahun 2004

Tabel 7

Klasifikasi peringkat komposisi NI

\begin{tabular}{ccl} 
Peringkat & Kriteria & \multicolumn{1}{c}{ Predikat } \\
1 & $\mathrm{NI} \geq 6,5 \%$ & Sangat Sehat \\
2 & $2,01 \% \leq \mathrm{NI}<6,5 \%$ & Sehat \\
3 & $1,5 \% \leq \mathrm{NI}<2 \%$ & Cukup Sehat \\
4 & $0 \% \leq \mathrm{NI}<1,9 \%$ & Kurang Sehat \\
5 & $\mathrm{ROE}<0 \%$ & Tidak Sehat \\
\hline Sumber : SE BI No. 6/23/DPNP tahun 2004
\end{tabular}


Tabel 8

Klasifikasi peringkat komposisi FDR

\begin{tabular}{ccl} 
Peringkat & Kriteria & \multicolumn{1}{c}{ Predikat } \\
\hline 1 & $50 \%<$ FDR $\leq 75 \%$ & Sangat Sehat \\
2 & $75 \%<$ FDR $\leq 85 \%$ & Sehat \\
3 & $85 \%<$ FDR $\leq 100 \%$ & Cukup Sehat \\
4 & $100 \%<$ FDR $\leq 120 \%$ & Kurang Sehat \\
5 & FDR $>120 \%$ & Tidak Sehat \\
\hline Sumber : SE BI No. $6 / 23 /$ DPNP tahun 2004
\end{tabular}

\section{METODOLOGI PENELITIAN}

Metode deskriptif kuantitatif dalam penelitian ini menggunakan yaitu dengan memberikan gambaran mengenai tingkat kesehatan perbankan syariah dalam bentuk angka-angka yang kemudian diuraikan dalam bentuk pembahasan (Pratikto et al., 2021).

Jenis data yang penulis gunakan adalah jenis data sekunder berupa laporan keuangan selama lima tahun terakhir sejak tahun 2016 sampai tahun 2020 dari data website resmi PT BPR Syariah Buana Mitra Perwira.

Teknik pengumpulan data yang penulis gunakan dalam penelitianini adalah teknik dokumentasi dari library research berupa studi pustaka melalui laporan keuangan perusahaan, Jurnal dan Buku yang terkait, untuk menganalisis tingkat kesehatan pada PT BPR Syariah Buana Mitra Perwira diTahun 2016 - 2020, maka dapat menggunakan metode CAMEL yang memiliki beberapa indicator yaitu permodalan,
Kualitas ases (asset quality), manajemen (management), rentabilitas (earning) dan likuiditas (liquidity) (Citra \& Merentek, 2013).

\section{HASIL DAN PEMBAHASAN \\ Modal (Capital)}

Modal merupakan faktor pertama untuk menilai kesehatan bank menurut metode CAMEL. Modal adalah penilaian modal yang dapat diukur dengan menggunakan rasio kecukupan modal (CAR). Rasio ini menjelaskan kemampuan bank untuk menggunakan modalnya untuk mengimbangi penurunan aset yang disebabkan oleh kerugian yang disebabkan oleh penggunaan aset tersebut (Tambuwun \& Sondakh, 2015). Berdasarkan tabel 9 diketahui bahwa rasio CAR pada PT BPR SyariahBuana Mitra Perwira dari tahun ke tahun mengelami kenaikan dan penurunan secara signifikan. Dapat dilihat pada tahun 2016 sebesar $16 \%$, pada tahun 2017 sebesar 19\%, pada tahun 2018 sebesar $15 \%$, pada tahun 2019 sebesar 16\% dan pada tahun 
2020 sebesar $17 \%$. Maka dapat disimpulkan bahwa CAR pada PT BPR Syariah Buana Mitra Perwira tahun 2016-2020 termasuk kategori yang sengat sehat.

\section{Kualitas (Asset Quality)}

Pada aspek kualitas aset ini dapat dilihat berdasarkan kelancaran pembayaran terdiri dari lancar, mendapat perhatian khusus, kurang lancar, diragukan sampai macet. Pada kualitas aset dihitung menggunakan indikator NPF dengan cara membandingkan antara kredit bermasalah dengan total kredit. Total NPF dari PT BPR Syariah Buana Mitra Perwira ditunjukkan pada tabel 10. Berdasarkan tabel 10 diketahui bahwa NPF pada PT BPR Syariah Buana Mitra Perwira dari tahun 2016 dan 2017 mengalami kenaikan. Dibuktikan dengan tahun 2016 sebesar 3.44\% dan pada tahun 2017 meningkat menjadi sebesar 5.39\%. Sedangkan pada tahun 2018 dan 2019 mengalami penurunan. Dibukuktikan pada tahun 2018 sebesar $6.49 \%$ dan pada tahun 2019 menurun menjadi sebesar 5.25\%.
Namun pada tahun 2020 sebesar 5.75\%. Maka dapat disimpulkan bahwa NPF pada PT BPR Syariah Buana Mitra Perwira tahun 2016-2020 termasuk kategori yang sengat sehat.

\section{Manajemen (Management)}

Management merupakan salah satu tolak ukur masyarakat terhadap suatu perbankan dengan melihat pengelolaan yang dilakukan, apakah sudah sesuai dengan peraturan yang ada atau tidak. Pengukuran tingkat kesehatan aspek manajemen menggunakan indikator PDN. Total PDN pada pada PT BPR Syariah Buana Mitra Perwira ditunjukkan tabel 11. Berdasarkan tabel 11 diketahui bahwa rasio PDN pada PT BPR Syariah BuanaMitra Perwira dari tahun 2016 sampai dengan tahun 2020 mengalami statistik yang sama. Maka dapat disimpulkan bahwa PDN pada PT BPR Syariah Buana Mitra Perwira tahun 2016-2020 termasuk kategori yang sangat sehat karena tidak terjadi pelanggaran satupun.

Tabel 9

Nilai Total CAR di BPR Syari'ah Buana Mitra tahun 2016 - 2020

\begin{tabular}{cc} 
Tahun & Nilai CAR (\%) \\
2016 & $16 \%$ \\
2017 & $19 \%$ \\
2018 & $15 \%$ \\
2019 & $16 \%$ \\
2020 & $17 \%$ \\
\hline Sumber : Hasil Olah Data, 2021
\end{tabular}


Tabel 10

Nilai Total NPF di BPR Syari'ah Buana Mitra tahun 2016 - 2020

\begin{tabular}{cc} 
Tahun & Nilai NPF (\%) \\
\hline 2016 & $3,44 \%$ \\
2017 & $5,39 \%$ \\
2018 & $6,49 \%$ \\
2019 & $5,25 \%$ \\
2020 & $5,75 \%$ \\
\hline
\end{tabular}

Sumber : Hasil Olah Data, 2021

Tabel 11

Nilai Total PDN di BPR Syari'ah Buana Mitra tahun 2016 - 2020

\begin{tabular}{cc} 
Tahun & Nilai PDN (\%) \\
2016 & $0,00 \%$ \\
2017 & $0,00 \%$ \\
2018 & $0,00 \%$ \\
2019 & $0,00 \%$ \\
2020 & $0,00 \%$ \\
\hline \multicolumn{2}{c}{ Sumber : Hasil Olah Data, 2021 }
\end{tabular}

\section{Rentabilitas (Earning)}

1. ROA (Return on Total Assets)

ROA menunjukkan hasil (return) atas jumlah aktiva yang telah digunakan oleh perusahaan maupun lembaga keuangan perbankan. ROA merupakan salah satu ukuran mengenai efektivitas dari manajemen dalam memanfaatkan aktivanya untuk memperoleh laba. Total ROA pada pada PT BPR Syariah Buana Mitra Perwira ditunjukkan tabel 12. Berdasarkan tabel 12 di atas diketahui bahwa rasio ROA pada PT BPR Syariah Buana Mitra Perwira dari tahun 2016 sebesar 2\%, pada tahun 2017 sebesar 3\%, pada tahun 2018 sebesar 3\% dan untuk tahun 2019 sebesar 3\%. Untuk
ROA mengalami kenaikan ditahun 20162017, namun tidak mengalami peningkatan maupun kenaika ditahun 2017-2020. Maka dapat disimpulkan bahwa ROA pada PT BPR Syariah Buana Mitra Perwira tahun 2016-2020 termasuk kategori yang sehat.

2. $\mathrm{ROE}$

Hasil dari ROE rentabilitas modal sendiri merupakan efensiensi penggunaan modal sendiri yang digunakan untuk mengukur kemampuan manajemen bank dalam melakukan pengendalian terhadap biaya operasional terhadap pendapatan operasional, rasio yang digunakan untuk mengukur laba bersih sesudah pajak dengan modal sendiri 
yang dimiliki oleh perusahaan. Total ROE pada pada PT BPR Syariah Buana Mitra Perwira ditunjukkan tabel 13. Berdasarkan tabel 13 diketahui bahwa rasio ROE pada PT BPR Syariah Buana Mitra Perwira sebesar 35\% ditahun 2016, mengalami kenaikan ditahun 2017 menjadi sebesar 46\%. Namun pada tahun 2018 mengalami penurunan menjadi sebesar $37 \%$, kamudian pada tahun 2019 mengalami kenaikan kembali menjadi sebesar 39\%. Pada tahun 2020 mengalami penurunan menjadi sebesar 35\%. Maka dapat disimpulkan ROE pada PT BPR Syariah Buana Mitra Perwira dikategorikan Sehat.

3. BOPO

Merupakan tingkat efesiensi lembaga keuangan untuk kegiatan operasionalnya dan mengetahui kemampuan mengukur rasio yang digunakanperbankan. Total BOPO pada pada PT BPR Syariah Buana Mitra Perwira ditunjukkan tabel 14. Berdasarkan tabel 14 diketahui bahwa rasio BOPO pada PT BPR Syariah Buana Mitra Perwira dari tahun 2016 sebesar 54\%, kemudian pada tahun 2017 sebesar 54\%, tahun 2018 sebesar 50\%, dan pada tahun 2019 sebesar 74\%. Mengalami penurunan secara signifikan menjadi sebesar 72\% ditahun 2020 . Maka dapat disimpulkan bahwa BOPO pada PT BPR Syariah Buana Mitra Perwira tahun 2016-2020 dikategorikan sangat sehat.

4. Rasio INI

Merupakan rasio yang digunakan oleh lembaga keuangan maupun perusahaan untuk mengukur besarnya pendapatan imbalan bersih yang dihasilkan dari aktiva produktif. Total NI pada pada PT BPR Syariah Buana Mitra Perwira ditunjukkan tabel 15. Berdasarkan tabel 15 diketahui bahwa rasio NI pada PT BPR Syariah Buana Mitra Perwira dari tahun 2016 sampai dengan tahun 2017 mengalami kenaikan tidak banyak, di buktikan pada tahun 2016 sebesar 35,78\% lalu meningkat pada tahun 2017 menjadi sebesar 38,3\%. Namun pada tahun 2019 sampai dengan tahun 2020 terus menerus mengalami penurunan secarasignifikan. Hal ini dibuktikan pada tahun 2018 sebesar 34,5\%, tahun 2019 menjadisebesar 32,8\% dan tahun 2020 menjadi sebesar 29,43\%. Maka dapat disimpulkan bahwa NI pada PT BPR Syariah Buana Mitra Perwira tahun 2016-2020 dikategorikan sangat sehat.

5. Likuiditas

Dalam menilai tingkat kesahatan bank menggunakan likuiditas dapat diukur 
menggunakan indikator FDR. Memiliki kemampuan pada rasio FDR dalam memenuhi semua kewajiban bank, khusunya dalam jangka waktu pendek yang dapat dikatakan bahwa bank likuiditas. Total FDR pada pada PT BPR Syariah Buana Mitra Perwira sesuai tabel 16. Berdasarkan tabel 16 diketahui bahwa rasio FDR pada PT BPR Syariah Buana Mitra Perwira sebesar $71 \%$ di tahun 2016, kemudian sebesar $71 \%$ ditahun 2017 Namun ditahun 2018 menjadi sebesar $82 \%$ kemudian pada tahun 2019 mengalami kenaikan kembali menjadi sebesar $85 \%$. Namun pada tahun 2020 kembali mengalami penurunan menjadi sebesar $82 \%$. Maka dapat disimpulkan bahwa NI pada PT BPR Syariah Buana Mitra Perwira tahun 2016-2020 dikategorikan cukup sehat.

Tabel 12

Nilai Total ROA di BPR Syari'ah Buana Mitra tahun 2016 - 2020

\begin{tabular}{cc} 
Tahun & Nilai ROA (\%) \\
2016 & $2 \%$ \\
2017 & $3 \%$ \\
2018 & $3 \%$ \\
2019 & $3 \%$ \\
2020 & $3 \%$ \\
\multicolumn{2}{|l}{ Sumber : Hasil Olah Data, 2021}
\end{tabular}

Tabel 13

Nilai Total ROE di BPR Syari'ah Buana Mitra tahun 2016 - 2020

\begin{tabular}{cc} 
Tahun & Nilai ROE (\%) \\
2016 & $35 \%$ \\
2017 & $46 \%$ \\
2018 & $37 \%$ \\
2019 & $39 \%$ \\
2020 & $35 \%$ \\
\hline
\end{tabular}

Sumber : Hasil Olah Data, 2021

Tabel 14

Nilai Total BOPO di BPR Syari'ah Buana Mitra tahun 2016 - 2020

\begin{tabular}{cc} 
Tahun & Nilai BOPO (\%) \\
\hline 2016 & $54 \%$ \\
2017 & $54 \%$ \\
2018 & $50 \%$ \\
2019 & $74 \%$ \\
2020 & $72 \%$ \\
\hline
\end{tabular}

Sumber : Hasil Olah Data, 2021 
Tabel 15

Nilai Total NI di BPR Syari'ah Buana Mitra tahun 2016 - 2020

\begin{tabular}{cc} 
Tahun & Nilai NI (\%) \\
2016 & $37,5 \%$ \\
2017 & $38,3 \%$ \\
2018 & $34,5 \%$ \\
2019 & $32,8 \%$ \\
2020 & $29,43 \%$ \\
\hline \multicolumn{2}{c}{ Sumber : Hasil Olah Data, 2021 } \\
& Tabel 16
\end{tabular}

Nilai Total FDR di BPR Syari'ah Buana Mitra tahun 2016 - 2020

\begin{tabular}{cc} 
Tahun & Nilai FDR (\%) \\
\hline 2016 & $71 \%$ \\
2017 & $71 \%$ \\
2018 & $82 \%$ \\
2019 & $85 \%$ \\
2020 & $82 \%$ \\
\hline
\end{tabular}

Sumber : Hasil Olah Data, 2021

\section{KESIMPULAN}

Dalam melakukan pengukuran pada tingkat kesehatan bank menggunakan metode CAMEL, analisis rasio CAR di PT BPR Syariah Buana Mitra Perwira tahun 2016- 2020 dikategorikan sangat sehat. Kemudian analisis rasio NPF dikategorikan sangat sehat. Selain itu, analisis rasio PDN PT BPR Syariah Buana Mitra Perwira tahun 20162020 dikategorikan sangat sehat, karena tidak ada satupun pelanggaran yang terjadi. Sedangkan analisis Rentabilitas menggunakan rasio ROA pada PT BPR Syariah Buana Mitra Perwira tahun 20162020 dikategorikan sehat, tetapi untuk analisis rasio ROE, BOPO dan NI pada PT BPR Syariah Buana Mitra Perwira tahun 2016-
2020 dikategorikan sangat sehat. Serta analisis rasio FDR pada PT BPR Syariah Buana Mitra Perwira tahun 2016-2020 dikategorikan cukup sehat. Dengan demikian menunjukkan bahwa tingkat kesehatan dalam sangat sehat serta mampu untuk mengahadapi pengaruh negatif dari fluktuasi bisnis yang sedang dihadapi.

\section{ACKNOWLEDGMENT}

Peneliti mengucapkan Terima kasih kepada Dosen Program Studi Ekonomi Syariah UIN Sunan Ampel Surabaya dan pihak dari BPR Syariah Buana Mitra Perwira tahun yang telah mendukung dan membantu memberikan data informasi laporan keuangan, sehingga penelitian ini dapat dilaksanakan dengan baik. 


\section{DAFTAR PUSTAKA}

Azwa, S., \& Afriani, S. (2014). Analisis Kinerja Keuangan Pada PT . Bank Pembiayaan Rakyat Syariah. Jurnal Ekonomi, 156-168.

Citra, K., \& Merentek, C. (2013). Analisis Kinerja Keuangan Antara Bank Negara Indonesia (BNI) dan Bank Mandiri Menggunakan Metode CAMEL. Jurnal EMBA, 1(3), 645-652.

Hafiz, Putra, A. (2018). Penilaian Tingkat Kesehatan Bank Syariah Dengan Metode Camel Dan Regc (Studi Pada Bank Bni Syariah Tahun 2011-2015). Ittizam Journal Of Shariah Economic Research, 2(1), 66-83.

Indonesia, B. (n.d.). Peraturan Bank Indonesia No. 9/1/PBI/2007 Sistem Penilaian Tingkat Kesahatan Bank Umum Berdasarkan Prinsip Syariah Pasal 13.

Iqbal, M., Pratikto, S., Afiq, M. K., Syariah, E., \& Distress, F. (2021). Analisis Tingkat Kesehatan Bank Dan Potensi Financial Distress Menggunakan Metode RGEC Dan Zmijewski Pada BNI Syariah Tahun 2015-2019. Jurnal Ekonomi Syariah Dan Terapan, 8(5), 570-581.

https://doi.org/10.20473/vol8iss20215pp570-581

Jacob, Dennis, Kevin, J. (2011). Analisis Laporan Keuangan Dengan Menggunakan Metode Camel Untuk Menilai Tingkat Kesehatan Perbankan. Jurnal EMBA, 1(3), 691700 .

Jafar, R., Basalamah, S., \& Rahim, S. (2020). Analisis Kesehatan Keuangan Perbankan Syariah Di Indonesia Menggunakan Metode CAMEL. Jurnal Ilmu Ekonomi, 3(1), 1-9.

Pratikto, M. I. S., Fabrela, C. B., \& Basya, M. M. (2021). Analisis Kesehatan Laporan Keuangan pada PT Bank Muamalat Indonesia Tbk dengan Menggunakan Metode Camel Tahun 2015-2019. OECONOMICUS Journal of Economics, 5(2), 75-85. https://doi.org/10.15642/oje.2021.5.2.75-85

Putri, Aprilia, Y., \& Marlius, D. (2018). Analisis Tingkat Kesehatan Bank Pada PT. Bank Perkreditan Rakyat (BPR) Jorong Kampuang Tangah Pariaman Cabang Padang. Jurnal Open Scince Framework, 1-10.

Sari, Kurnia, R. (2019). Analisis kesehatan bank dengan metode camel(studi kasus : PT. Bank Tabungan Negara, Tbk periode 2011-2015). Jurnal MONEX, 8, 208-215.

Syahputra, R. (2018). Analisis Tingkat Kesehatan Bank Dengan Metode Camel Pada PT Bank Artos Indonesia Tbk Periode 2014-2017. Jurnal Akuntansi Dan Bisnis, 4(1).

Tambuwun, C. J., \& Sondakh, J. J. (2015). Analisis Laporan Keuangan Sebagai Ukuran Kesehatan Bank Dengan Metode Camel Pada PT. Bank Sulut. Jurnal EMBA, 3(2), 863873. 